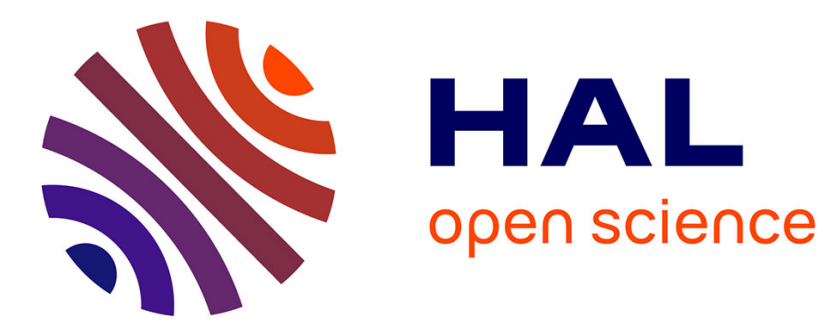

\title{
Homogeneous and heterogeneous catalytic (dehydrogenative) oxidation of oleochemical 1,2-diols to $\alpha$-hydroxyketones
}

Nam Duc Vu, Boris Guicheret, Nicolas Duguet, Estelle Métay, Marc Lemaire

\section{- To cite this version:}

Nam Duc Vu, Boris Guicheret, Nicolas Duguet, Estelle Métay, Marc Lemaire. Homogeneous and heterogeneous catalytic (dehydrogenative) oxidation of oleochemical 1,2-diols to $\alpha$-hydroxyketones. Green Chemistry, 2017, 19 (14), pp.3390-3399. 10.1039/c7gc00867h . hal-03252477

\section{HAL Id: hal-03252477 \\ https://hal.science/hal-03252477}

Submitted on 7 Jun 2021

HAL is a multi-disciplinary open access archive for the deposit and dissemination of scientific research documents, whether they are published or not. The documents may come from teaching and research institutions in France or abroad, or from public or private research centers.
L'archive ouverte pluridisciplinaire HAL, est destinée au dépôt et à la diffusion de documents scientifiques de niveau recherche, publiés ou non, émanant des établissements d'enseignement et de recherche français ou étrangers, des laboratoires publics ou privés. 


\title{
Homogeneous and Heterogeneous Catalytic (Dehydrogenative) Oxidation of Oleochemical 1,2-Diols to $\alpha$-Hydroxyketones
}

\author{
Nam Duc Vu, Boris Guicheret, Nicolas Duguet,* Estelle Métay* and Marc Lemaire
}

The preparation of methyl oleate $\alpha$-hydroxyketone from the corresponding 1,2-diol has been investigated with both homogeneous and heterogeneous systems. Homogeneous conditions using $\mathrm{Pd}(\mathrm{OAc})_{2} /$ neocuproine complex were first developed using oxygen as sole oxidant under mild conditions (MeOH, $50^{\circ} \mathrm{C}$ ). Under these conditions, the conversion of diol reached $95 \%$ and the $\alpha$-hydroxyketone was obtained with $97 \%$ selectivity. The access to $\alpha$ hydroxyketone has also been studied by dehydrogenation using a range of heterogeneous catalysts under solvent-free conditions at high temperature (160$180^{\circ} \mathrm{C}$ ). Dehydrogenation using activated Ru/C under vacuum gave the $\alpha$-hydroxyketone with $93 \%$ conversion and $82 \% \mathrm{GC}$ yield. The optimized conditions were applied to a range of oleochemical diols, including a vegetable oil derivative, to give the corresponding $\alpha$-hydroxyketones with up to $74 \%$ isolated yields.

\section{Introduction}

Vegetable oils (triglycerides) are attractive renewable raw materials for the chemical industry. ${ }^{1}$ Indeed, they are widely available (about 202 million tons in 2015) ${ }^{2}$ and relatively inexpensive. For instance, they can be used as biofuel ${ }^{3}$ (biodiesel) but this application is subject of controversy and only pertinent when the price of fossil resources is high. To date, they can be best converted to valuable building blocks for a wide range of applications. ${ }^{4}$ Unsaturated oleochemicals are particularly interesting for the installation of a wide range of organic functions. On the one hand, unsaturated plant oils could be directly (co)-polymerized to give functional materials such as Linoleum and alkyd resins. ${ }^{5}$ Epoxidized plant oils could also be used for the formation of epoxy resins and their polyolderived analogs for the formation of polyesters and polyurethanes. On the other hand, unsaturated fatty acid derivatives have been intensively studied for the introduction of a wide range of organic functions ${ }^{6}$ including aldehyde, ${ }^{7}$ epoxide, ${ }^{8}$ diol, ${ }^{9}$ ketone and diketone, ${ }^{10}$ carbonate, ${ }^{11}$ among others. ${ }^{12}$ Comparatively, there are only few studies related to the $\alpha$-hydroxyketone function on fatty acid compounds. So far, these derivatives have been mainly used for the preparation of heterocyclic fatty compounds. ${ }^{13}$ More recently, our group has reported an original method for the cleavage of methyl oleate $\alpha$-hydroxyketone. ${ }^{14}$ This method gives access to the corresponding aldehydes, i.e., nonanal and methyl azelaaldehydate, that could be used as building-blocks for the preparation of surfactants ${ }^{15}$ and polymers. ${ }^{16}$ More importantly, the process occurs under non-oxidative conditions and could therefore constitute a safer alternative to reductive ozonolysis. ${ }^{17}$ In this context, the development of a scalable, economical and environmentally-friendly method for the preparation of fatty $\alpha$-hydroxyketones is highly desirable.

In early reports, oleic acid was directly used as starting material for the preparation of 9(10)-hydroxy-10(9)-oxo-stearic acid using "neutral" $\mathrm{KMnO}_{4}$ (Scheme 1, path a). ${ }^{18}$ Apart from using a stoichiometric oxidant, these methods require high dilutions and gave low yields. However, a fine control of $\mathrm{pH}$ (phosphate buffer) could generate the desired $\alpha$ hydroxyketone with $61 \%$ yield. ${ }^{18 f}$ Inspired by the pioneer's work of Cohen and Tsuji,19 Brousse and Lefort have prepared methyl 9(10)-hydroxy-10(9)-oxostearate by oxidative ringopening of methyl 9,10-epoxystearate using DMSO as an oxidant in the presence of catalytic $\mathrm{BF}_{3} . \mathrm{Et}_{2} \mathrm{O}$ (Scheme 1, path b). ${ }^{20}$ In their report, the $\alpha$-hydroxyketone was obtained with $65 \%$ yield but we have observed that the method suffers from a lack of reproducibility. ${ }^{21} \mathrm{~A}$ similar procedure was applied to cis- and trans-9,10-epoxystearic acids but the reaction provided low yields. ${ }^{22}$ Furthermore, both methods generate dimethyl sulfide as malodorous and toxic gas, thus compromising the scale-up. Alternatively, 9,10-diketostearic acid, prepared by $\mathrm{KMnO}_{4}$ oxidation of stearolic acid, ${ }^{23}$ could also serve as starting material for the generation of the $\alpha$ hydroxyketone function (Scheme 1, path c). ${ }^{24}$ Reduction of the $\alpha$-dioxo-acid using zinc in acetic acid afforded the ketol-acid with up to $88 \%$ yield. ${ }^{18 f}$ The mono-oxidation of erythro-9,10dihydroxystearic acid has also been investigated using $\mathrm{N}$ bromosuccinimide (NBS) as an oxidant (Scheme 1, path d). Under these conditions, the corresponding $\alpha$-ketol-acid was obtained with $63 \%$ yield (based on recovery of starting material) with inevitable formation of the corresponding $\alpha$ dioxo-acid, thus complicating the purification. ${ }^{18 f}$ All these routes are of great interest to access fatty $\alpha$-hydroxyketone derivatives, however, they usually imply the use of stoichiometric (toxic) reagents.

The mono-oxidation of (secondary) 1,2-diols to $\alpha$ hydroxyketones represents a challenge in terms of chemoselectivity due to competing over-oxidation, dehydration and carbon-carbon cleavage reactions. Several stoichiometric methods have been reported based on silver carbonate on Celite (Fetizon reagent), ${ }^{25}$ dioxiranes, ${ }^{26}$ stannylene acetal oxidation, ${ }^{27} \quad \mathrm{NaBrO}_{3} / \mathrm{NaHSO}_{3}{ }^{28}$ and $\mathrm{KBrO}_{3} / \mathrm{KHSO}_{4}$ reagents. ${ }^{29}$ However, most of these methods suffer from concomitant overoxidation, functional group incompatibilities, lack of selectivity, low yields as well as the generation of a large quantities of waste. Catalytic methods have also been reported based on $\mathrm{Sn}-\mathrm{Br}_{2},{ }^{30}$ boronic aciddibromoisocyanuric acid (DBI), ${ }^{31} \mathrm{Ru}$-oxone, ${ }^{32} \mathrm{Cu}-\mathrm{NBS}^{33}$ and $\mathrm{Pd}$ benzoquinone systems. ${ }^{34}$ However, these methods rely on oxidants that generate a lot of waste, and therefore, they are not compatible with green chemistry principles. Other systems based on homogeneous- $\mathrm{Pd}^{34}$ and peroxotungstophosphate ${ }^{35}$ 
are probably more promising as they use greener oxidants such as $\mathrm{O}_{2}$ (or air) and $\mathrm{H}_{2} \mathrm{O}_{2}$, respectively. From an ecological point of view, the preparation of $\alpha$-hydroxyketones by catalytic dehydrogenation of 1,2-diols is more advantageous as it generates only hydrogen as byproduct. To the best of our knowledge, there are only two reports for the dehydrogenation of 1,2-diols using metallic $\mathrm{Cu}^{36}$ or $\mathrm{Ir}$ $\mathrm{ReO}_{x} / \mathrm{SiO}_{2}{ }^{37}$ as heterogeneous catalysts. These systems require high temperatures $\left(220-260^{\circ} \mathrm{C}\right)$ and have never been applied to challenging substrates such as vegetable oils derivatives.

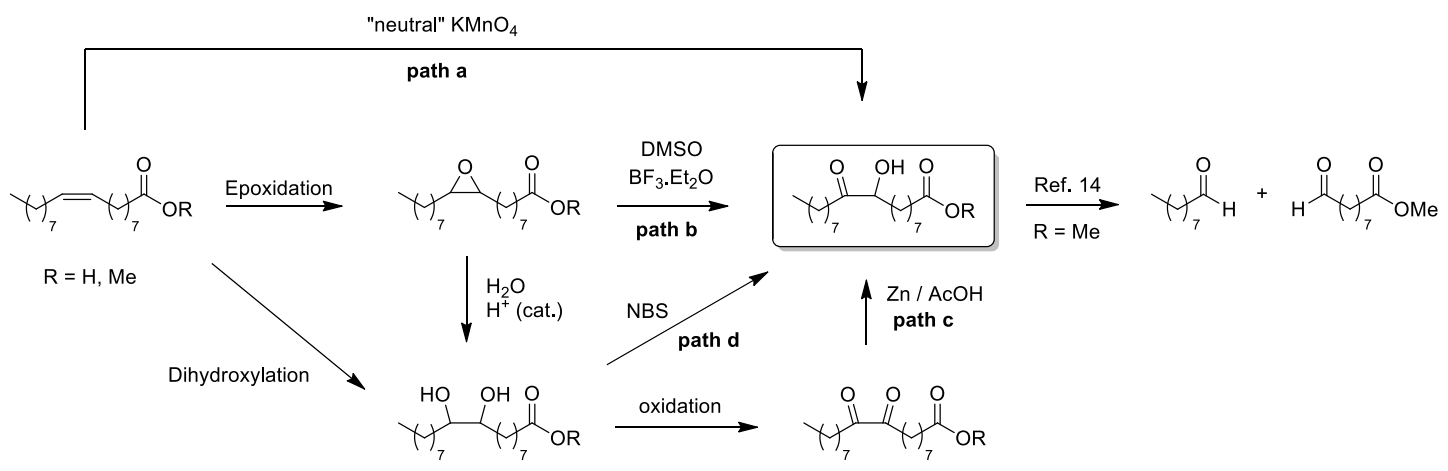

Scheme 1. Preparative routes to $\alpha$-hydroxyketone from oleic acid and methyl oleate.

In this context, we have developed two methodologies to prepare $\alpha$-hydroxyketones from fatty 1,2-diols using both catalytic homogeneous-palladium and heterogeneousruthenium systems (Scheme 2). High selectivities ( $\approx 90 \%)$ towards the formation of the desired $\alpha$-hydroketone function were achieved under solvent-free conditions.

$\begin{gathered}\text { b) heterogeneous } \\ \text { [Ru] cat. }\end{gathered}$
$[\mathrm{Pd}]$ cat. $/ \mathrm{O}_{2}$

Scheme 2. Catalytic preparation of $\alpha$-hydroxyketone from fatty acid-derived 1,2-diols.

\section{Results and discussion}

\section{Homogeneous-palladium system.}

Waymouth et al. have recently reported the selective oxidation of glycerol to dihydroxyacetone (DHA) using a $\mathrm{Pd}(\mathrm{OAc})_{2} /$ neocuproine complex $^{38}$ in the presence of benzoquinone as oxidant. ${ }^{34 a}$ Inspired by this work, we have first attempted the selective monooxidation of methyl 9,10dihydroxystearate under their optimized conditions [5 mol\% $\mathrm{Pd}, 3$ equiv benzoquinone, $\mathrm{CH}_{3} \mathrm{CN}$ or DMSO, $\mathrm{rt}, 20^{\circ} \mathrm{C}$. However, no $\alpha$-hydroxyketone has been detected probably due to the lack of solubility of the starting material. Thus, the reaction conditions have been reinvestigated and benzoquinone has been substituted by oxygen as a cleaner oxidant. Initially, the oxidation of methyl 9,10-dihydroxy stearate has been carried out in a sealed tube using Pdneocuproine catalytic system (4 mol\%), oxygen ( 1 bar) in $\mathrm{MeOH}$ at $50^{\circ} \mathrm{C}$ for 3 hours (Table 1 ). Under these conditions, the conversion reached $54 \%$ and the selectivity towards the formation of $\alpha$-hydroxyketone $\mathbf{2}$ (1:1 mixture of regioisomers) attained $91 \%$ (Table 1 , entry 1 ). The concentration of starting material 1 was progressively increased and the best selectivity (93\%) was obtained for 1.5 M (Table 1, entries 2-3). Realizing that the pressure of oxygen gradually decreases as the reaction progresses, it was then carried out in a stainless steel reactor using a constant pressure of oxygen (3 bar). Gratifyingly, the conversion was complete after 3 hours and the selectivity was preserved around $90 \%$ (Table 1 , entry 4 ). Moreover, an additional experiment has shown that the reaction is complete within 30 minutes (Table 1 , entry 5). Similar results (99\% conversion, $89 \%$ selectivity) were also obtained using only 2 mol\% of catalyst, provided an extended reaction time (Table 1 , entry 6 ). Finally, further decreasing the catalyst loading to $1 \mathrm{~mol} \%$ did not allow reaching complete conversion (Table 1, entry 7).

Table 1. Catalytic oxidation of methyl 9,10-dihydroxystearate with Pd-neocuproine complex $^{a}$

\begin{tabular}{|c|c|c|c|c|c|c|}
\hline 1 & OMe & $\begin{array}{c}\mathrm{O}_{2} \\
(\mathrm{OAc})_{2}(4 \mathrm{~mol} \%) \\
\text { ocuproine }(4 \mathrm{~mol} \% \\
\mathrm{MeOH}, 50^{\circ} \mathrm{C}, 3 \mathrm{~h}\end{array}$ & $+(1: 1 \mathrm{n}$ & 2 & . & $\mathrm{H}_{7}^{\mathrm{O}}$ \\
\hline Entry & $\begin{array}{c}{[\mathbf{1}]} \\
\left(\mathrm{mol} . \mathrm{L}^{-1}\right)\end{array}$ & $\begin{array}{c}\text { Pd } \\
\text { complex } \\
\text { (mol\%) }\end{array}$ & $\begin{array}{l}\text { Time } \\
\text { (h) }\end{array}$ & $\begin{array}{c}\text { Conv. }^{b} \\
\text { (\%) }\end{array}$ & $\begin{array}{c}\text { Sel. } 2^{b} \\
(\%)\end{array}$ & $\begin{array}{c}\text { Sel. } 3^{b} \\
(\%)\end{array}$ \\
\hline 1 & 0.5 & 4 & 3 & 54 & 91 & 5 \\
\hline 2 & 1.5 & 4 & 3 & 58 & 93 & 1 \\
\hline 3 & 3 & 4 & 3 & 77 & 90 & 2 \\
\hline $4^{c}$ & 1.5 & 4 & 3 & $>99$ & 90 & 10 \\
\hline $5^{c}$ & 1.5 & 4 & 0.5 & $>99$ & 90 & 10 \\
\hline $6^{c}$ & 1.5 & 2 & 1.5 & 99 & 89 & 8 \\
\hline $7^{c}$ & 1.5 & 1 & 1 & 67 & 93 & 2 \\
\hline
\end{tabular}

a Reaction conditions: $20-\mathrm{mL}$ sealed tube, $3 \mathrm{mmol}$ of $1, \mathrm{Pd}(\mathrm{OAc})_{2}$ (4 mol\%), neocuproine ( $4 \mathrm{~mol} \%), \mathrm{O}_{2}$ ( 1 bar), $\mathrm{MeOH}(2-6 \mathrm{~mL}), 50^{\circ} \mathrm{C}, 3$ hours. ${ }^{b}$ Determined by GC. ${ }^{c}$ Reaction carried out in a 30-mL stainless steel reactor using diol 1 (4 g, 12 $\mathrm{mmol}), \mathrm{O}_{2}$ (3 bar, 0.5 equiv), $\mathrm{MeOH}(8 \mathrm{~mL})$.

The effect of the ligand's structure on the catalytic activity was next probed on the model reaction using previously optimized 
conditions. No reaction was observed with pyridine-2,6dicarboxylic acid. Strikingly, only neocuproine could efficiently catalyze the reaction as structurally-related ligands such as 3,4,7,8-tetramethyl-1,10-phenanthroline and 1,10phenanthroline only returned starting material (Figure 1).
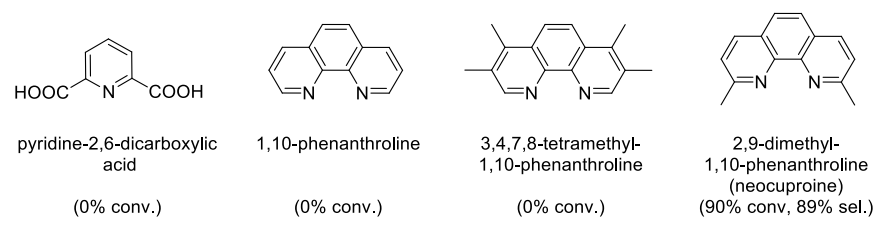

Figure 1. Ligands tested in the Pd-catalyzed monooxidation of 1,2-diols.

According to Waymouth's work, ${ }^{34}$ steric hindrance arising from the presence of two methyl groups in neocuproine would prevent the formation of a stable dimeric complex. An active monomeric $\mathrm{Pd}(\mathrm{II})$ complex would be favoured, allowing the coordination of 1,2-diol, and leading to the formation of the desired $\alpha$-hydroxyketone. In contrast, the use of other phenanthroline ligands leads to more stable complexes that are unable to catalyze this transformation, at least, under the conditions used. Finally, the presence of neocuproine was found essential for catalytic activity as the reaction proceeds very slowly (6\% conversion) without ligand.

Various oxidants were next screened for the monooxidation of 1,2-diol 1 under the previously optimized conditions (Table 2). Under an air flow at atmospheric pressure, the conversion only reached $48 \%$ (Table 2, entry 1 ). However, the conversion increased to 58 and $92 \%$ using 0.5 and 1 equivalent of $\mathrm{O}_{2}$, respectively (Table 2 , entries $2-3$ ). Satisfyingly, the selectivity towards 2 still remained around 90\%. Excellent results (95\% conversion and $99 \%$ selectivity) were obtained with benzoquinone ( 1 equiv) as an oxidant. Moreover, the conversion can be further improved to $>99 \%$ using 2 equivalents but the selectivity dropped to $70 \%$ due to overoxidation to diketone 3 (Table 2, entries 4-5). Despite that excellent results could be attained with this oxidant, this procedure generates hydroquinone as a by-product which represents a lot of waste to eliminate or to recycle. Hydrogen peroxide was also found an adequate oxidant to promote the formation of $\alpha$-hydroxyketone $\mathbf{2}$ with a satisfying $83 \%$ conversion and $91 \%$ selectivity (Table 2 , entry 6 ). Contrary to benzoquinone, increasing the amount of oxidant did not affect the selectivity but led to a poor $26 \%$ conversion (Table 2 , entry 7). This result has been attributed to the ability of $\mathrm{H}_{2} \mathrm{O}_{2}$ to oxidize the methyl groups of neocuproine, affecting the structural integrity of the ligand and thus decreasing the reaction rate of reaction.
Table 2. Screening of oxidants. ${ }^{a}$

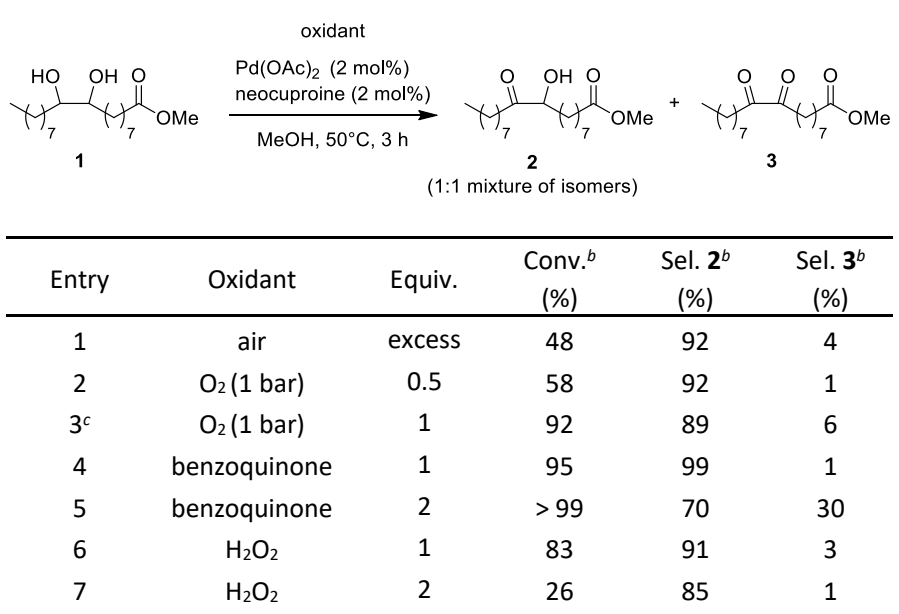

a Reaction conditions: $20-\mathrm{mL}$ sealed tube, $3 \mathrm{mmol}$ of $1, \mathrm{Pd}(\mathrm{OAc})_{2}$ (2 mol\%), neocuproine (2 mol\%), $\mathrm{MeOH}(2 \mathrm{~mL}), 50^{\circ} \mathrm{C}, 3$ hours. ${ }^{b}$ Determined by GC. ${ }^{c} 1.5$ $\mathrm{mmol}$ of 1 .

From these results, oxygen was conserved as the most desirable oxidant from an atom-economy point of view since it only generates water as by-product. Another strategy to improve the selectivity towards the formation of $\mathbf{2}$ has been investigated using an exogenous acid (Table 3 ). Indeed, it is assumed from previous reports ${ }^{34,38,39}$ that a monocationic $\mathrm{Pd}(\mathrm{II})$-hydride complex is generated after the release of the $\alpha$ hydroxyketone. Moreover, this $\mathrm{Pd}(\mathrm{II})$-hydride could form a $\mathrm{Pd}(0)$-neocuproine complex by the loss of a proton. Insertion of molecular oxygen into either $\mathrm{Pd}(\mathrm{II})$-hydride or $\mathrm{Pd}(0)$ neocuproine complexes should yield $\mathrm{Pd}(\mathrm{II})$-hydroperoxo ${ }^{40}$ or $\mathrm{Pd}(\mathrm{II})$-peroxo ${ }^{41}$ complexes, respectively. Addition of acetic acid onto these species should reform the active monomeric $\mathrm{Pd}(\mathrm{II})$ complex, thus maintaining the catalytic performances of the system. ${ }^{41}$ Based on these mechanistic considerations, we hypothesized that acetic acid could have a beneficial effect on both the conversion and the selectivity. Treatment of diol $\mathbf{1}$ with a catalytic amount of acetic acid (3 mol\%) under the optimized conditions led a slight improvement of the selectivity to $92 \%$ (Table 3 , entries $1-2$ ).

Table 3. Aerobic Pd-catalyzed oxidation of 1,2-diol in the presence of $\mathrm{AcOH} .{ }^{a}$

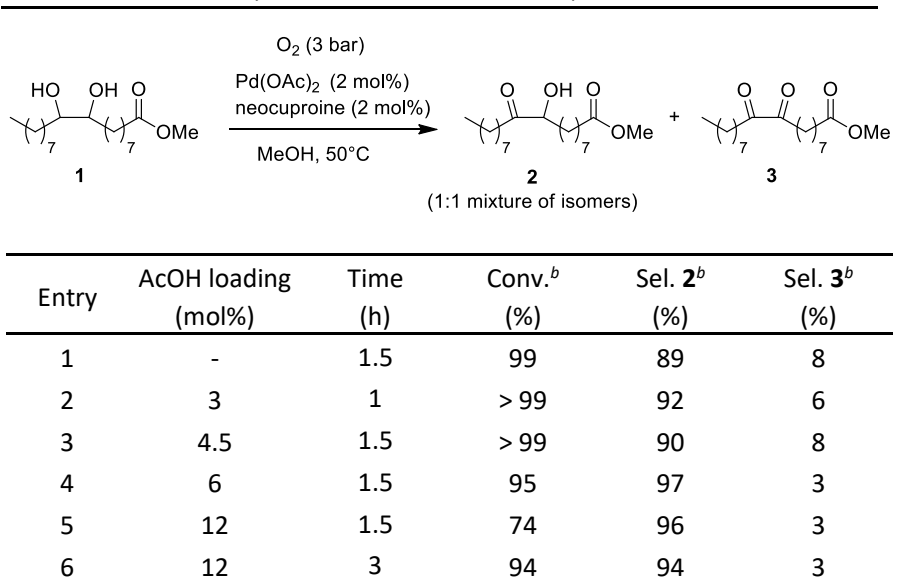

a Reaction conditions: $30-\mathrm{mL}$ stainless steel reactor, $12 \mathrm{mmol}$ of $1, \mathrm{Pd}(\mathrm{OAc})_{2}(2$ mol\%), neocuproine (2 mol\%), $\mathrm{O}_{2}(3 \mathrm{bar}), \mathrm{MeOH}(8 \mathrm{~mL}), 50^{\circ} \mathrm{C} .{ }^{b}$ Determined by GC. 
Satisfyingly, an excellent $97 \%$ selectivity was obtained when the quantity of acetic acid was gradually increased from 3 to 6 mol\% (Table 3, entries 3-4). Further increasing the additive loading did not improve the selectivity and the conversion dropped to $74 \%$ (Table 3, entry 5). However, it could be restored to $94 \%$ after a prolonged time (Table 3, entry 6). These results clearly indicate that the catalytic activity of the Pd-neocuproine complex is significantly affected in the presence of $\mathrm{AcOH}$.

The scope of the reaction was then investigated (Table 4). Treatment of diol $\mathbf{1}$ under optimized conditions gave $\alpha$ hydroxyketone $\mathbf{2}$ with $80 \%$ isolated yield after purification by column chromatography (Table 4 , entry 1 ). Diol 4 derived from tert-butyl oleate gave similar results and $\alpha$-hydroxyketone $\mathbf{8}$ was obtained with $78 \%$ yield (Table 4 , entry 2 ). Symmetrical diols 5 and $\mathbf{6}$ were next considered. These starting materials could be prepared from the corresponding alkenes formed by self-metathesis of methyl oleate, ${ }^{42}$ however, other synthetic routes have been preferred for convenience. On the one hand, diol 5 was prepared through a NHC-catalysed benzoin condensation of nonanal followed by catalytic hydrogenation. ${ }^{43}$ On the other hand, diol 6 was prepared from biobased (Z)-1,18-octadec-9-enedioic acid obtained by biotransformation of oleic acid. ${ }^{44}$ Catalytic oxidation of diols $\mathbf{5}$ and 6 gave the corresponding $\alpha$-hydroxyketones $\mathbf{9}$ and $\mathbf{1 0}$ with 84 and $61 \%$ yield, respectively (Table 4 , entries $3-4$ ). It should be noted that, even if the conversion is lower with diol 6, both substrates gave around $90 \%$ selectivity. Finally, diol $\mathbf{7}$ derived from methyl erucate gave full conversion and $\alpha$ hydroxyketone 11 was isolated with $72 \%$ yield (Table 4 , entry 5). In that case, the selectivity dropped to $74 \%$ due to overoxidation to the corresponding diketone and to the formation of unidentified by-products. All these fatty $\alpha$ hydroxyketones are of potential interest to access bio-based aldehydes through retro-benzoin cleavage.

Table 4. Scope of the catalytic oxidation of fatty acid-derived 1,2-diols to alpha-hydroxyketones. ${ }^{\circ}$

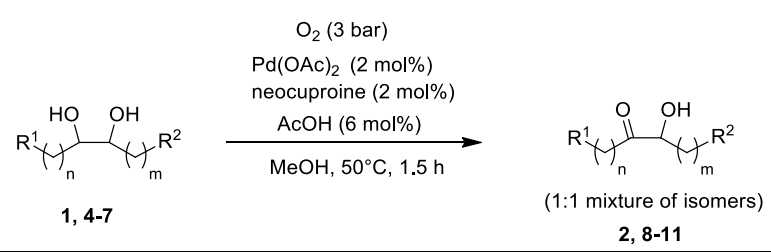

\begin{tabular}{|c|c|c|c|c|c|c|}
\hline Entry & 1,2-Diol & Conv. $^{b}(\%)$ & Alpha-hydroxyketone & & $\begin{array}{c}\text { Isolated } \\
\text { Yield }^{c}(\%)\end{array}$ & $\begin{array}{c}\text { Selectivity }^{b} \\
(\%)\end{array}$ \\
\hline 1 & & 95 & & 2 & 80 & $\begin{array}{c}97 \\
(3 \% \text { DK) }\end{array}$ \\
\hline 2 & & 99 & & 8 & 78 & $\begin{array}{c}80 \\
(14 \% \text { DK) }\end{array}$ \\
\hline 3 & & 99 & & 9 & 84 & $\begin{array}{c}90 \\
(9 \% \text { DK) }\end{array}$ \\
\hline 4 & & 75 & & 10 & 61 & $\begin{array}{c}92 \\
\text { (no DK) }\end{array}$ \\
\hline 5 & & 99 & & 11 & 72 & $\begin{array}{c}74 \\
(12 \% \text { DK) }\end{array}$ \\
\hline
\end{tabular}

${ }^{a}$ Reaction conditions: $30-\mathrm{mL}$ stainless steel reactor, $12 \mathrm{mmol}$ of 1,2-diol, $\mathrm{Pd}(\mathrm{OAc})_{2}$ ( $\left.2 \mathrm{~mol} \%\right)$, neocuproine $(2 \mathrm{~mol} \%), \mathrm{AcOH}(6 \mathrm{~mol} \%), \mathrm{O}_{2}(3 \mathrm{bar}), \mathrm{MeOH}(8 \mathrm{~mL}), 50^{\circ} \mathrm{C}, 1.5$ hour. ${ }^{b}$ Conversion and selectivity were determined by ${ }^{1} \mathrm{H}$ NMR. ${ }^{c}$ Isolated yield after purification by column chromatography. DK $=1,2$-diketone.

\section{Heterogeneous-ruthenium system.}

Although exhibiting excellent performances, the $\mathrm{Pd}$ neocuproine complex has the inherent drawbacks of homogeneous systems, that are short-term stability and limited recyclability. In this context, the development of a complementary methodology using a heterogeneous catalytic system is highly desirable. Moreover, such robust systems are particularly adequate to prepare $\alpha$-hydroketones by catalytic dehydrogenation of 1,2-diols, that is usually requiring elevated temperatures. First, a range of commercially available heterogeneous catalysts was screened at $160^{\circ} \mathrm{C}$ under solventfree conditions (Table 5). 
Table 5. Screening of heterogeneous catalysts. ${ }^{a}$

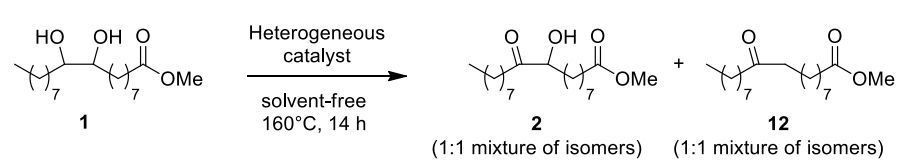

(1:1 mixture of isomers) (1:1 mixture of isomers)

\begin{tabular}{ccccc}
\hline Entry & Catalyst & $\begin{array}{c}\text { Loading } \\
(\text { mol\%) }\end{array}$ & $\begin{array}{c}\text { Conv. }^{b} \\
(\%)\end{array}$ & $\begin{array}{c}\text { Sel. }^{b} \\
(\%)\end{array}$ \\
\hline 1 & $5 \%-\mathrm{Pd} / \mathrm{SiO}_{2}$ & 2.5 & 0 & - \\
2 & $5 \%-\mathrm{Pd} / \mathrm{Al}_{2} \mathrm{O}_{3}$ & 2.5 & 0 & - \\
3 & $10 \%-\mathrm{Pd} / \mathrm{BaSO}_{4}$ & 2.5 & 0 & - \\
4 & $5 \%-\mathrm{Pt} / \mathrm{SiO}_{2}$ & 2.5 & 0 & - \\
5 & $5 \%-\mathrm{Ru}_{2}$ & 2.5 & 20 & 35 \\
6 & $5 \%-\mathrm{Ru} / \mathrm{Al}_{2} \mathrm{O}_{3}$ & 2.5 & 45 & 29 \\
7 & $5 \%-\mathrm{Ru}(\mathrm{OH})_{\times} / \mathrm{Al}_{2} \mathrm{O}_{3}$ & 2.5 & 50 & 60 \\
8 & $10 \%-\mathrm{Ru}(\mathrm{OH})_{\times} / \mathrm{Al}_{2} \mathrm{O}_{3}$ & 5 & 62 & 64 \\
9 & $\mathrm{Al}_{2} \mathrm{O}_{3}$ & 5 & - & -
\end{tabular}

a Reaction conditions: $20-\mathrm{mL}$ sealed tube, argon atmosphere, $3 \mathrm{mmol}$ of $1 .^{b}$ Determined by GC.

Supported palladium catalysts gave no conversion while platinum on silica gave poor results (Table 5, entries 1-4). On the contrary, all ruthenium-based catalysts were found to be active for the dehydrogenation of $\mathbf{1}$ but with important disparities regarding the nature of the support. Both $\mathrm{Ru} / \mathrm{C}$ and $\mathrm{Ru} / \mathrm{Al}_{2} \mathrm{O}_{3}$ gave moderate selectivities but better conversion was obtained with $\mathrm{Al}_{2} \mathrm{O}_{3}$ (Table 5, entries 5-6). The replacement of $\mathrm{Ru} / \mathrm{Al}_{2} \mathrm{O}_{3}$ by $\mathrm{Ru}(\mathrm{OH})_{\times} / \mathrm{Al}_{2} \mathrm{O}_{3}$ - Mizuno's catalyst - gave $50 \%$ conversion and $60 \%$ selectivity and improved results could be obtained with a higher catalyst loading (Table 5, entries 7-8). Finally, control experiment with $\mathrm{Al}_{2} \mathrm{O}_{3}$ gave poor results, indicating the important role of Ru species in the dehydrogenation process (Table 5, entry 9). This initial screening has been carried out in sealed tube in order to select a suitable catalyst for the dehydrogenation process. However, the conversions are limited, probably due to the fact that hydrogen generated from the dehydrogenation process remains in the tube, thus preventing to shift the equilibrium towards the formation of the alpha-hydroxyketone. In order to circumvent this problem, hydrogen scavengers such as 1octene or 4-vinylanisole were used. However, the results could not be improved and partial polymerization of scavengers was observed at high temperature. Consequently, another strategy to shift the equilibrium has been envisioned by removing hydrogen under vacuum (Table 6). Thus, diol 1 was heated at $170^{\circ} \mathrm{C}$ in the presence of $10 \%-\mathrm{Ru}(\mathrm{OH})_{\times} / \mathrm{Al}_{2} \mathrm{O}_{3}(5 \mathrm{~mol} \%)$ and hydrogen was removed at 5 mbar. Gratifyingly, the conversion increased to $78 \%$ and the selectivity reached $90 \%$ (Table 6 , entry 1 ). Increasing the temperature to $180^{\circ} \mathrm{C}$ improved the conversion to $91 \%$ but the selectivity dropped to $75 \%$ (Table 6 , entry 2). An excellent $99 \%$ selectivity was obtained with $5 \%$ $\mathrm{Ru} / \mathrm{Al}_{2} \mathrm{O}_{3}$ but the conversion plateaued at $70 \%$ and could not be improved with a prolonged time (Table 6, entry 3). Using $5 \%-\mathrm{Ru} / \mathrm{C}$ gave $80 \%$ conversion and $94 \%$ selectivity towards the formation of 2 (Table 6, entry 4). These results were encouraging, however, a mass loss of about $10 \%$ was noticed for all these experiments.
Table 6. Dehydrogenation of diol 1 under vaccum ${ }^{a}$

$$
\underset{1}{\stackrel{\substack{\text { solvent-free } \\ \mathrm{T}\left({ }^{\circ} \mathrm{C}\right) \\ \text { vacuum }=5 \mathrm{mbar}}}{(1: 1 \text { mixture of isomers })}}
$$

\begin{tabular}{ccccccc}
\hline Entry & Catalyst & $\begin{array}{c}\text { Loading } \\
(\mathrm{mol} \%)\end{array}$ & Conditions & $\begin{array}{c}\text { Conv. }^{b} \\
(\%)\end{array}$ & $\begin{array}{c}\text { Sel. } 2^{b} \\
(\%)\end{array}$ & $\begin{array}{c}\text { Mass } \\
\text { balance } \\
(\%)\end{array}$ \\
\hline 1 & $10 \%-\mathrm{Ru}(\mathrm{OH})_{\times} / \mathrm{Al}_{2} \mathrm{O}_{3}$ & 5 & $170^{\circ} \mathrm{C}, 8 \mathrm{~h}$ & 78 & 90 & 8 \\
2 & $10 \%-\mathrm{Ru}(\mathrm{OH})_{\times} / \mathrm{Al}_{2} \mathrm{O}_{3}$ & 5 & $180^{\circ} \mathrm{C}, 8 \mathrm{~h}$ & 91 & 75 & 10 \\
3 & $5 \%-\mathrm{Ru} / \mathrm{Al}_{2} \mathrm{O}_{3}$ & 5 & $170^{\circ} \mathrm{C}, 8 \mathrm{~h}$ & 70 & 99 & 10 \\
4 & $5 \%-\mathrm{Ru} / \mathrm{C}$ & 5 & $170^{\circ} \mathrm{C}, 8 \mathrm{~h}$ & 80 & 94 & 10
\end{tabular}

${ }^{a}$ Reaction conditions: $30-\mathrm{mL}$ Schlenk flask fitted with a condenser, $12 \mathrm{mmol}$ of $\mathbf{1}$. $b$ Determined by GC.

This phenomenon has been attributed to the evaporation of the monoketone $\mathbf{1 2}$ produced by dehydration under these reaction conditions. In order to avoid such inconvenience, the vacuum pressure was progressively increased and it was found that applying a vacuum of 100 mbar led to similar results but without any mass loss. Therefore, the efficiency of the dehydrogenation process was re-investigated under these conditions (Figure 2). For that purpose, only commercially available $\mathrm{Ru} / \mathrm{Al}_{2} \mathrm{O}_{3}$ and $\mathrm{Ru} / \mathrm{C}$ catalysts were considered and a temperature of $175^{\circ} \mathrm{C}$ has been selected as a compromise to maintain high conversion and selectivity.

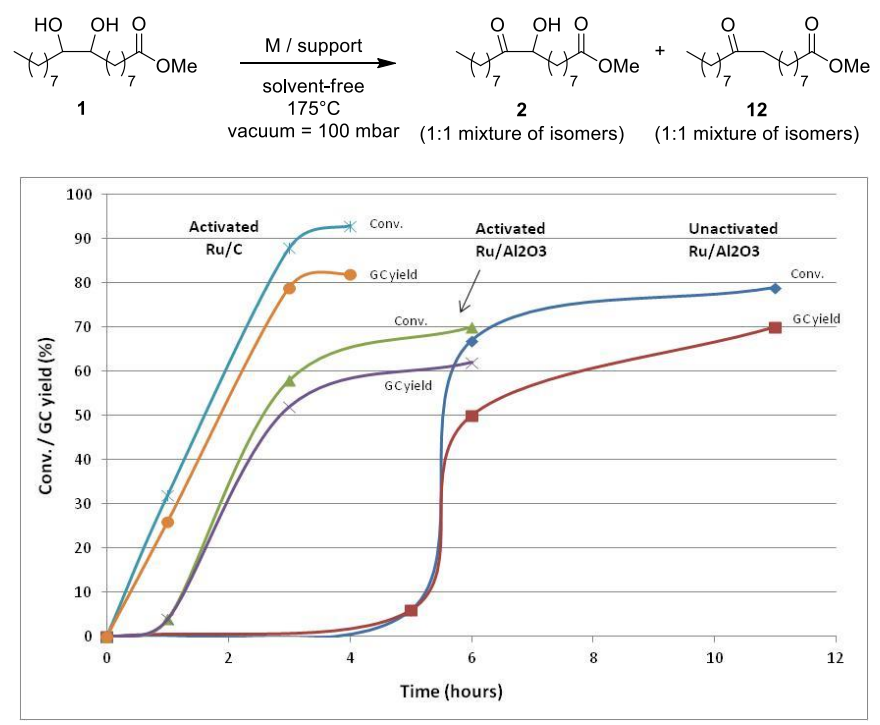

Figure 2. Dehydrogenation with unactivated or activated catalysts.

Unactivated $\mathrm{Ru} / \mathrm{Al}_{2} \mathrm{O}_{3}$ gave $79 \%$ conversion of diol $\mathbf{1}$ and $70 \%$ GC yield after $11 \mathrm{~h}$ at $175^{\circ} \mathrm{C}$ (Figure 2, dark blue and red curves). Interestingly, almost no activity was detected during the first four hours. Intrigued by this observation, $\mathrm{Ru} / \mathrm{Al}_{2} \mathrm{O}_{3}$ was activated under an atmospheric hydrogen pressure for $1 \mathrm{~h}$ at $175^{\circ} \mathrm{C}$. Using this activated catalyst, the dehydrogenation process was much faster. However, the conversion could not exceed $70 \%$ after 6 hours and the GC yield only attained $62 \%$ (Figure 2, green and purple curves). Activated $\mathrm{Ru} / \mathrm{C}$ gave an even better activity with $93 \%$ conversion and $82 \%$ GC yield 
after only $4 \mathrm{~h}$ (Figure 2, light blue and orange curves). These results show that activation under hydrogen is essential for the catalytic activity but does not affect the selectivity. Indeed, the selectivity was maintained to $88-89 \%$ whatever the catalyst.

The scope of the dehydrogenation of fatty acid-derived 1,2diols was then investigated under the optimized conditions [activated Ru/C (5 mol\%), solvent-free, vacuum of $100 \mathrm{mbar}$, $175^{\circ} \mathrm{C}, 3$ hours)] (Table 7). These starting materials were prepared from the corresponding alkenes through a two-step epoxidation / ring-opening sequence, unless otherwise stated. ${ }^{43}$ Diols 1, 13-14 obtained from methyl, $n$-butyl and 2ethylhexyl oleate gave good conversions (71-91\%) and good selectivities (87-92\%) and the corresponding $\alpha$ hydroxyketones 2, 17-18 were obtained with 56-67\% isolated yields (Table 7, entries 1-3). Diol 4 obtained from tert-butyl oleate was also subjected to the dehydrogenation conditions. Full conversion was obtained but no desired product was detected (Table 7, entry 4). Only diol 19 and its corresponding $\alpha$-hydroxyketone 20, lacking the tert-butyl group, were detected by GC. We hypothesized that $\mathrm{Ru} / \mathrm{C}$ is acidic enough to promote de-tert-butylation under these conditions. Indeed, this process, usually catalysed by a wide range of acids, 45 could be accelerated under vacuum with the removal of iso-butene. In order to prevent de-tert-butylation, diol 4 was treated with activated $\mathrm{Ru} / \mathrm{Al}_{2} \mathrm{O}_{3}$ to give the desired $\alpha$-hydroxyketone 8 with $28 \%$ isolated yield (Table 7 , entry 5 ). Dehydrogenation of diols 5 and 6 gave 93-94\% conversion and 79-76\% GC yield (Table 7, entries 6-7). The corresponding $\alpha$-hydroxyketones 9-10 were recovered with 74 and $57 \%$ isolated yield, respectively. The protocol was then extended to diols from other fatty acid methyl esters. Diol 7 derived from methyl erucate gave 85\% conversion and $\alpha$-hydroxyketone 11 was obtained with $46 \%$ isolated yield (Table 7, entry 8). Diol 15 derived from 12-Oacetyl methyl ricinoleate was also subjected to dehydrogenation. Despite a complete conversion, only traces of the desired $\alpha$-hydroxyketone were detected by GC. Conversely, tetrahydrofurans $\mathbf{2 1 a}$ and $\mathbf{2 1}$ b were isolated with $60 \%$ yield and obtained as a 2:1 inseparable mixture of diastereomers (Table 7, entry 9). ${ }^{46}$ These compounds are supposedly formed by acid-catalysed 1,4-migration of the acetyl group followed dehydrative intramolecular cyclisation. A similar product (with free hydroxy group) has been reported by Werner during the preparation of carbonate from epoxidized methyl ricinoleate, thus supporting this hypothesis. ${ }^{11 \mathrm{c}}$ The replacement of $\mathrm{Ru} / \mathrm{C}$ by $\mathrm{Ru} / \mathrm{Al}_{2} \mathrm{O}_{3}$ for the dehydrogenation of diol $\mathbf{1 5}$ did not allow the preparation of the desired $\alpha$-hydroxyketone. Finally, in order to push forward this methodology, tris(diol) 16, prepared from high oleic sunflower oil, was subjected to the dehydrogenation conditions (Table 7 , entry 10). The corresponding tris $(\alpha-$ hydroxyketone) $\mathbf{2 2}$ was produced with a moderate $42 \%$ yield (determined by ${ }^{1} \mathrm{H}$ NMR). This result demonstrates that the method is also applicable to challenging substrates such as vegetable oil derivatives.

The recyclability of the heterogeneous $\mathrm{Ru} / \mathrm{C}$ catalyst has been assessed using 1,2-diol $\mathbf{1}$ as model substrate using our standard conditions [activated ${ }^{5 \mathrm{wt}} \% \mathrm{Ru} / \mathrm{C}$ ( $5 \mathrm{~mol} \%$ ), solvent-free, $175^{\circ} \mathrm{C}, 3$ hours under a vacuum of $100 \mathrm{mbar}$ ] (Figure 3 ).

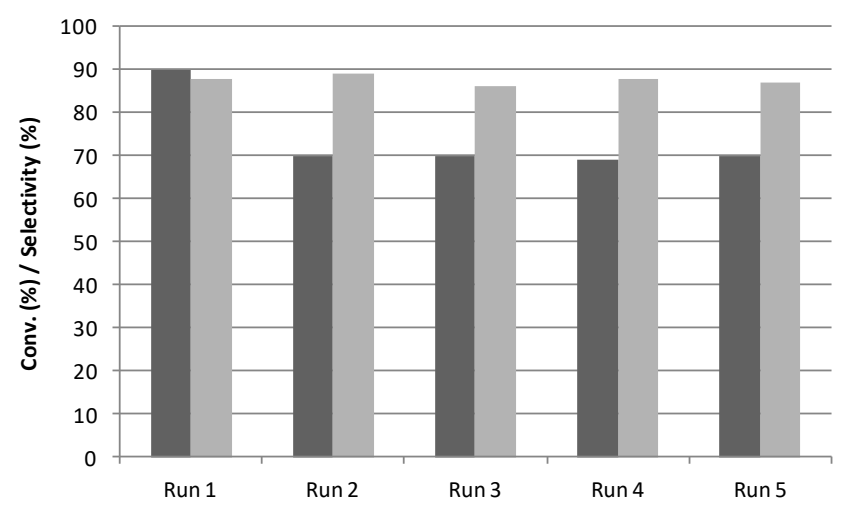

Figure 3. Recycling of the heterogeneous Ru/C catalyst. Conversion (\%) of 1,2-diol 1 (black) and selectivity (\%) of $\alpha$-hydroxyketone $\mathbf{2}$ (gray).

The first run was carried out using freshly activated $\mathrm{Ru} / \mathrm{C}$ and gave $90 \%$ conversion of diol 1 and $88 \%$ selectivity for the $\alpha$ hydroxyketone $\mathbf{2}$. These results are very close from those previously obtained (Table 7, entry 1) showing the good reproducibility of the method. After reaction, the catalyst was filtered, washed throughly (EtOAc), dried at $120^{\circ} \mathrm{C}$ under vacuum and re-activated under hydrogen. ${ }^{47}$ Under these conditions, the conversion reached $70 \%$ and similar results were obtained for the next runs. Gratifyingly, the selectivity remained constant around $88-89 \%$ for all runs. The loss in conversion between runs 1 and 2 suggests some Ru leaching, however, it seems quite unlikely because the filtrate has no significant catalytic activity. A more reasonable explanation is the change in the oxidation degree of the $\mathrm{Ru} / \mathrm{C}$ catalyst as recently shown in a recent work on a commercial $\mathrm{Ru} / \mathrm{C}$ catalyst. ${ }^{48}$ Further studies will be carried out to understand the activation/deactivation processes and the results will be reported in due course. 


$$
\begin{gathered}
\begin{array}{c}
\text { solvent-free } \\
175^{\circ} \mathrm{C}, 3 \mathrm{~h} \\
\text { vacuum }=100 \mathrm{mbar}
\end{array} \\
\text { (1:1 mixture of isomers })
\end{gathered}
$$

\begin{tabular}{|c|c|c|c|c|c|c|c|}
\hline Entry & Diol & & Conv. $^{b}(\%)$ & Alpha-hydroxyketone & & GC Yield $^{b}(\%)$ & Selectivity \\
\hline 1 & & 1 & 91 & & 2 & $79(67)$ & 87 \\
\hline 2 & & 13 & 75 & & 17 & $69(65)$ & 92 \\
\hline 3 & & 14 & 71 & & 18 & $63(56)$ & 89 \\
\hline 4 & & 4 & 99 & & $\begin{array}{l}19 \\
20\end{array}$ & - & - \\
\hline $5^{c}$ & & 4 & 40 & & 8 & $35(28)$ & 88 \\
\hline 6 & & 5 & 93 & & 9 & $79(74)$ & 85 \\
\hline 7 & & 6 & 94 & & 10 & $76(57)$ & 81 \\
\hline 8 & & 7 & 85 & & 11 & $69(46)$ & 81 \\
\hline 9 & & 15 & $>99$ & & 21a, & (60) & - \\
\hline $10^{d, e}$ & & 16 & 50 & & 22 & 42 (nd) & 84 \\
\hline
\end{tabular}

${ }^{a}$ Reaction conditions: 20-mL Schlenk flask, Ru/C was activated under atmospheric hydrogen pressure for $1 \mathrm{~h}$ at $175^{\circ} \mathrm{C}, 3 \mathrm{mmol}$ of diol. ${ }^{b}$ Determined by GC. ${ }^{c}$ Activated $\mathrm{Ru} / \mathrm{Al}_{2} \mathrm{O}_{3}$ was used. ${ }^{d}$ Conversion and yield were determined by ${ }^{1} \mathrm{H}$ NMR. ${ }^{e}$ The reaction was carried out in 6 hours.

\section{Conclusions}

In conclusion, we have developed two complementary methods for the preparation of $\alpha$-hydroxyketones derived from fatty acids. The monooxidation of methyl oleate-derived diol using homogeneous $\mathrm{Pd}(\mathrm{OAc})_{2} /$ neocuproine complex gave the corresponding $\alpha$-hydroxyketone with up to $97 \%$ selectivity under mild conditions $\left(\mathrm{MeOH}, 50^{\circ} \mathrm{C}\right)$. The access to alphahydroketone has also been investigated by dehydrogenation using heterogeneous ruthenium-based catalysts under solvent-free conditions at $175^{\circ} \mathrm{C}$. It has been shown that activated $\mathrm{Ru} / \mathrm{C}$ was the most active catalyst for this transformation and working under vacuum is essential to reach high conversion and selectivity. In addition, the catalyst was found to be recyclable over 5 runs without loss of selectivity. Finally, the optimized conditions were applied to a range of oleochemical 1,2-diols to give the corresponding $\alpha$ hydroxyketones with up to $74 \%$ isolated yields. These original 
fatty acid derivatives could be further functionalized or cleaved to the corresponding acids or aldehydes.

\section{Acknowledgements}

The authors thank the French National Agency for financial support through a Ph.D. grant to B.G. and a master grant to N.D.V. (ANR-13-CDII-0001-COUPOX). N.D.V. work was also performed during his Ph.D., in partnership with the SAS PIVERT, within the frame of the French Institute for the Energy Transition (Institut pour la Transition Energétique (ITE) P. I. V. E. R. T. (http://www.institut-pivert.com) selected as an Investment for the Future ("Investissements d'Avenir"). This work was supported, as part of the Investments for the Future, by the French Government under the reference ANR-001-01.

\section{Experimental}

Typical procedure for the preparation of $\alpha$-hydroxyketones using homogeneous $\mathrm{Pd}(\mathrm{OAc})_{2}$ / neocuproine complex:

In 30-mL steel reactor, methyl 9,10-dihydroxyoctadecanoate 1 (4 g, $12 \mathrm{mmol}$ ), $\mathrm{Pd}(\mathrm{OAc})_{2}$ (54 mg, $0.24 \mathrm{mmol}, 2 \mathrm{~mol} \%$ in $\mathrm{Pd}$ ), neocuproine (50 mg, $0.24 \mathrm{mmol}, 2 \mathrm{~mol} \%$ ) were successively introduced in $\mathrm{MeOH}(8 \mathrm{~mL})$ under stirring. The mixture was stirring at room temperature in a few minutes until the medium became more homogeneous. Next, glacial acetic acid (43 $\mathrm{mg}, 0.72 \mathrm{mmol}, 6 \mathrm{~mol} \%$ ) was added to the solution before closing the apparatus. Oxygen ( 3 bar) was charged in the reactor, then the reaction was heated at $50^{\circ} \mathrm{C}$ (oil bath) for 1.5 hour. The reaction mixture was cooled down to $25^{\circ} \mathrm{C}$ by stream of water before adding EtOAc $(20 \mathrm{~mL})$. The suspension was filtered and the filtrate was evaporated under reduced pressure to give a green oil (3.97 g). The crude product was purified by column chromatography on silica gel $\left(\mathrm{CH}_{2} \mathrm{Cl}_{2}\right.$ /EtOAC, 100:0 $\rightarrow$ 95:5) to give the $\alpha$-hydroxyketone 2 (3.20 g, 80\%) as white solid. See Supporting Information for the full characterization of the compound.

Typical procedure for the preparation of $\alpha$-hydroxyketones using heteregeneous $\mathrm{Ru} / \mathrm{C}$ :

In a Schlenk flash, methyl 9,10-dihydroxyoctadecanoate 1 ( $0.92 \mathrm{~g}, 2.8 \mathrm{mmol}$ ) and activated ${ }^{5 \%} \mathrm{Ru} / \mathrm{C}(0.26 \mathrm{~g}, 5 \mathrm{~mol} \%$ in $\mathrm{Ru})$ were introduced. Then, argon was filled inside the equipment. The outline of apparatus was connected with evaporator system to control the vacuum pressure at 100 mbar. The reaction was heated at $175^{\circ} \mathrm{C}$ (oil bath) for 3 hours. After cooling to room temperature, EtOAc $(2 \times 20 \mathrm{~mL})$ was added in the mixture then the resulting slurry was filtered though milipore system (pore $0.1 \mu \mathrm{m}$ ). The filtrate was evaporated under reduced pressure to give the crude product $(0.89 \mathrm{~g})$. The residue was purified by column chromatography on silica gel $\left(\mathrm{CH}_{2} \mathrm{Cl}_{2}\right.$ /EtOAC, 100:0 $\rightarrow$ 95:5) to give the $\alpha$-hydroxyketone 2 $(0.61 \mathrm{~g}, 67 \%)$ as white solid.

\section{Notes and references}

1 A. Corma, S. Iborra and A. Velty, Chem. Rev., 2007, 107, 2411-2502.

2 http://www.rea.co.uk/rea/en/markets/oilsandfats/worldpro duction, 2015.

3 a) F. Ma and M. A. Hanna, Bioresour. Technol., 1999, 70, 115; b) A. Srivastava and R. Prasad, Renewable Sustainable Energy Rev., 2000, 4, 111-113; c) A. Demirbas, Appl. Energy, 2011, 88, 17-28.

4 a) U. Biermann, W. Friedt, S. Lang, W. Lühs, G. Machmüller, J. O. Metzger, M. Rüsch gen. Klaas, H. J. Schäfer and M. P. Schneider, Angew. Chem. Int. Ed., 2000, 39, 2206-2224; Angew. Chem., 2000, 112, 2292-2310; b) U. Biermann, U. Bornscheuer, M. A. R. Meier, J. O. Metzger and H. J. Schäfer, Angew. Chem. Int. Ed. 2011, 50, 3854-3871; Angew. Chem. 2011, 123, 3938-3956; c) M. A. R. Meier, J. O. Metzger and U. S. Schubert, Chem. Soc. Rev., 2007, 36, 1788-1802; d) Y. Xia and R. C. Larock, Green Chem., 2010, 12, 1893-1909.

5 J. van Haveren, E. A. Oostveen, F. Micciche and J. G. J. Weijnen, Eur. Coat. J., 2005, 1-2, 16-19.

6 J. M. Fraile, J. I. García, C. I. Herrerías and E. Pires, Synthesis, 2017, DOI: 10.1055/s-0036-1588699.

7 For a review about hydroformylation of oleochemicals, see: T. Vanbésien, E. Monflier and F. Hapiot, Eur. J. Lipid Sci. Technol., 2016, 118, 26-35.

8 a) D. Mandelli, Y. N. Kozlov, W. A. Carvalho and G. B. Shul'pin, Catal. Commun., 2012, 26, 93-97; b) B.-J. Kollbe Ahn, S. Kraft and X. S. Sun, J. Agric. Food Chem., 2012, 60, 2179-2189.

9 a) B.-J. Kollbe Ahn, S. Kraftb and X. S. Sun, J. Mater. Chem., 2011, 21, 9498; b) M. Dierker and H. J. Schäfer, Eur. J. Lipid Sci. Technol., 2010, 112, 122-136.

10 K. M. Doll, G. B. Bantchev and R. E. Murray, ACS Sustainable Chem. Eng., 2013, 1, 39-45.

11 a) J. Langanke, L. Greiner and W. Leitner, Green Chem., 2013, 15, 1173-1182; b) N. Tenhumberg, H. Büttner, B. Schäffner, D. Kruse, M. Blumensteinc and T. Werner, Green Chem., 2016, 18, 3775-3788; c) H. Büttner, C. Grimmer, J. Steinbauer and T. Werner, ACS Sustainable Chem. Eng., 2016, 4, $4805-4814$.

12 T. Vanbésien, E. Monflier and F. Hapiot, Green Chem., 2016, 18, 6687-6694.

13 S. Fürmeier and J. O. Metzger, Eur. J. Org. Chem. 2003, 885893.

14 E. Deruer, N. Duguet and M. Lemaire, ChemSusChem, 2015, 8, 2481-2486.

15 For our contribution on the reductive alkylation of polyols with aldehydes, see: a) Y. Shi, W. Dayoub, A. Favre-Réguillon, G.-R. Chen and M. Lemaire, Tetrahedron Lett., 2009, 50, 6891-6893; b) Y. Shi, W. Dayoub, G.-R. Chen and M. Lemaire, Green Chem., 2010, 12, 2189-2195; c) C. Gozlan, R. Lafon, N. Duguet, A. Redl and M. Lemaire, RSC Adv., 2014, 4, 5065350661; d) M. Sutter, E. Da Silva, N. Duguet, Y. Raoul, E. Métay and M. Lemaire, Chem. Rev., 2015, 115, 8609-8651; e) C. Gozlan, E. Deruer, M.-C. Duclos, V. Molinier, J.-M. Aubry, A. Redl, N. Duguet and M. Lemaire, Green Chem., 2016, 18, 1994-2004; f) D. Belmessieri, C. Gozlan, M.-C. Duclos, V. Molinier, J.-M. Aubry, O. Dumitrescu, G. Lina, A. Redl, N. Duguet and M. Lemaire, Eur. J. Med. Chem., 2017, 128, 98-106.

16 a) J. Jose, G. Pourfallah, D. Merkley, S. Li, L. Bouzidi, A. Lopes Leaob and S. S. Narine, Polym. Chem., 2014, 5, 3203-3213; b) J. Jose, G. Pourfallah, A. Lopes Leaob and S. S. Narine, Polym. Int., 2014, 63, 1902-1911.

17 For recent examples of reductive ozonolysis of methyl oleate, see: a) K. Louis, L. Vivier, J.-M. Clacens, M. Brandhorst, J.-L. Dubois, K. De Oliveira Vigier and Y. Pouilloux, Green Chem., 2014, 16, 96-101; b) T. S. Omonov, E. Kharraz, P. Foleyb and J. M. Curtis, RSC Adv., 2014, 4, 
53617-53627; c) M. D. Lundin, A. M. Danby, G. R. Akien, T. P. Binder, D. H. Busch and B. Subramaniam, ACS Sustainable Chem. Eng., 2015, 3, 3307-3314.

18 a) D. Holde and J. Marcusson, Ber., 1903, 36, 2657-2662; b) G. King, J. Chem. Soc., 1936, 1788-1792; c) R. S. Morrell and E. O. Phillips, J. Soc. Chem. Ind., London, 1938, 57, 245-247; d) T. P. Hilditch and H. Plimmer, J. Chem. Soc., 1942, 204206; e) E. Coleman, C. Ricciuti and D. Swern, J. Am. Chem. Soc., 1956, 78, 5342-5345; f) W. A. Cramp, F. J. Julietti, J. F. McGhie, B. L. Rao and W. A. Ross, J. Chem. Soc., 1960, 42574263.

19 T. Cohen and T. Tsuji, J. Org. Chem., 1961, 26, 1681-1681.

20 E. Brousse and D. Lefort, C. R. Acad. Sc. Paris, 1965, 261, groupe 8, 1990-1991.

21 In our previous work (reference 14), we have prepared the alpha-hydroxyketone of methyl oleate from methyl 9,10epoxystearate following the procedure reported by Brousse and Lefort. However, a maximum yield of $43 \%$ could only be attained and the reaction sometimes failed to give the desired product, showing the lack of reproducibility of this method.

22 T. M. Santosusso and D. Swern, J. Org. Chem., 1975, 40, 2764-2769.

23 N. A. Khan, F. E. Deatherage and J. B. Brown, J. Am. Oil Chem. Soc., 1951, 28, 27-31.

24 J. F. McGhie, Chem. Ind., 1954, 131-132.

25 M. Fétizon, M. Golfier and J.-M. Louis, J. Chem. Soc. Chem. Commun., 1969, 1102-1102.

26 a) L. D'Accolti, A. Detomaso, C. Fusco, A. Rosa and R. Curci, J. Org. Chem., 1993, 58, 3600-3601; b) P. Bovicelli, P. Lupattelli and A. Sanetti, Tetrahedron Lett., 1995, 36, 3031-3034; c) P. Bovicelli, D. Truppa, A. Sanetti, R. Bernini and P. Lupattelli, Tetrahedron, 1998, 54, 14301-14314; d) W. Adam, C. R. Saha-Möller and C.-G. Zhao, Tetrahedron: Asymm., 1998, 9, 4117-4122; e) W. Adam, C. R. Saha-Möller and C.-G. Zhao, J. Org. Chem., 1999, 64, 7492-7497; f) K. Jakka and C.-G. Zhao, Org. Lett., 2006, 8, 3013-3015.

27 a) S. David and A. Thieffry, J. Chem. Soc., Perkin Trans. 1, 1979, 1568-1573; b) D. H. Crout and S. M. Morrey, J. Chem. Soc., Perkin Trans. 1, 1983, 2435-2440; c) T. Maki, K. Fukae, H. Harasawa, T. Ohishi, Y. Matsumura and O. Onomura, Tetrahedron Lett., 1998, 39, 651-654; d) T. Maki, S. likawa, G. Mogami, H. Harasawa, Y. Matsumura and O. Onomura, Chem.-Eur. J., 2009, 15, 5364-5370.

28 M. Bierenstiel, P. J. D'Hondt and M. Schlaf, Tetrahedron 2005, 61, 4911-4917.

29 J. M. William, M. Kuriyama and O. Onomura, Tetrahedron Lett., 2014, 55, 6589-6592.

30 J. M. William, M. Kuriyama and O. Onomura, RSC Adv., 2013, 3, 19247-19250.

31 J. M. William, M. Kuriyama and O. Onomura, Adv. Synth. Catal., 2014, 356, 934-940.

32 B. Plietker, Org. Lett., 2004, 6, 289-291.

33 O. Onomura, H. Arimoto, Y. Matsumura and Y. Demizu, Tetrahedron Lett., 2007, 48, 8668-8672.

34 a) R. M. Painter, D. M. Pearson and R. M. Waymouth, Angew. Chem., 2010, 122, 9646-9649; b) K. Chung, S. M. Banik, A. G. De Crisci, D. M. Pearson, T. R. Blake, J. V. Olsson, A. J. Ingram, R. N. Zare and R. M. Waymouth, J. Am. Chem. Soc., 2013, 135, 7593-7602; c) K. Chung and R. M. Waymouth, ACS Catal., 2016, 6, 4653-4659.

35 Y. Sakata and Y. Ishii, J. Org. Chem., 1991, 56, 6233-6235.

36 Á. Molnár and M. Bartók, React. Kinet. Catal. Lett., 1976, 4, 315-321.

37 H. Sato, M. Tamura, Y. Nakagawa and K. Tomishige, Chem. Lett., 2014, 43, 334-336.

38 a) N. R. Conley, L. A. Labios, D. M. Pearson, C. McCrory, C. E. D. Chidsey and R. M. Waymouth, Organometallics, 2007, 26 5447-5453; b) D. M. Pearson and R. M. Waymouth, Organometallics, 2009, 28, 3896-3900.
39 S. S. Stahl, Angew. Chem., Int. Ed. 2004, 43, 3400-3420.

40 a) T. Nishimura, T. Onoue, K. Ohe and S. Uemura, J. Org. Chem. 1999, 64, 6750-6755; b) M. C. Denney, N. A. Smythe, K. L. Cetto, R. A. Kemp and K. I. Goldberg, J. Am. Chem. Soc. 2006, 128, 2508-2509.

41 S. S. Stahl, J. L. Thorman, R. C. Nelson and M. A. Kozee, J. Am Chem. Soc. 2001, 123, 7188-7189.

42 For examples of self-metathesis of methyl oleate, see: a) J. C. Mol, Green Chem., 2002, 4, 5-13; b) A. Kajetanowicz, A Sytniczuk and K. Grela, Green Chem., 2014, 16, 1579-1585.

43 See supplementary information for full details.

44 a) Z. H. Yi and H. J. Rehm, Appl. Microbiol. Biotechnol., 1989, 30, 327-331; b) W. H. Eschenfeldt, Y. Zhang, H. Samaha, L. Stols, L. D. Eirich, C. R. Wilson and M. I. Donelly, Appl. Environ. Microbiol., 2003, 69, 5992-5999.

45 For examples of acid-catalysed de-tert-butylation of esters, see: a) E Marcantoni, M. Massaccesi and E. Torregiani, J. Org. Chem., 2001, 66, 4430-4432; b) P. Strazzolini, N. Misuri and P. Polese, Tetrahedron Lett., 2005, 46, 2075-2078; c) J. C. Lee, E. S. Yoo and J. S. Lee, Synthetic Commun., 2004, 34 3017-3020; d) D. H. Park and J. H. Park, Bull. Korean Chem. Soc., 2009, 30, 230-232; e) Y.-q. Wu, D. C. Limburg, D. E. Wilkinson, M. J. Vaal and G. S. Hamilton, Tetrahedron Lett., 2000, 41, 2847-2849.

46 The relative configuration of tetrahydrofurans was assigned by comparison with ${ }^{1} \mathrm{H}$ NMR data reported in the literature, see: T. H. Kalantar and K. B. Sharpless, Acta Chem. Scand., 1993, 47, 307-313.

47 When the second run is carried out with the recovered catalyst without reactivation under hydrogen, the conversion of diol only reached $60 \%$ but the selectivity for $\alpha$ hydroxyketone was preserved (88\%).

48 J. Jae, W. Zheng, A. M. Karim, W. Guo, R. F. Lobo and D. G. Vlachos, ChemCatChem, 2014, 6, 848-856. 